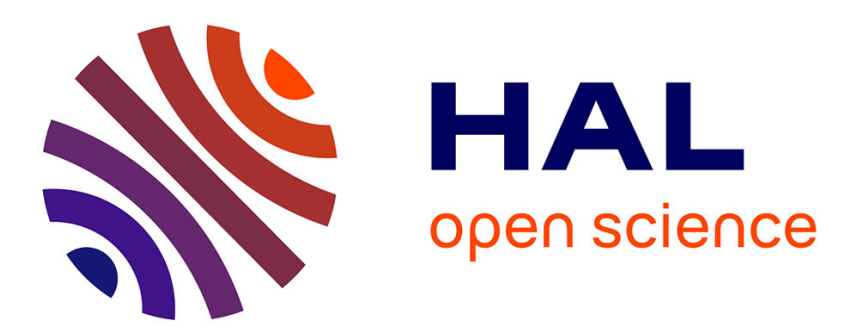

\title{
Green Formulation Strategy for Preparing Oil-in-Water Emulsions via Lipase-Catalyzed Transesterification
}

\author{
Natcha Wongthongdee, Alain Durand, Thunyarat Pongtharangkul, Panya
}

Sunintaboon, Pranee Inprakhon

\section{- To cite this version:}

Natcha Wongthongdee, Alain Durand, Thunyarat Pongtharangkul, Panya Sunintaboon, Pranee Inprakhon. Green Formulation Strategy for Preparing Oil-in-Water Emulsions via LipaseCatalyzed Transesterification. ACS Sustainable Chemistry \& Engineering, 2016, 5 (2), pp.1948-1956. 10.1021/acssuschemeng.6b02688 . hal-02055146

\section{HAL Id: hal-02055146 \\ https://hal.univ-lorraine.fr/hal-02055146}

Submitted on 20 Apr 2019

HAL is a multi-disciplinary open access archive for the deposit and dissemination of scientific research documents, whether they are published or not. The documents may come from teaching and research institutions in France or abroad, or from public or private research centers.
L'archive ouverte pluridisciplinaire HAL, est destinée au dépôt et à la diffusion de documents scientifiques de niveau recherche, publiés ou non, émanant des établissements d'enseignement et de recherche français ou étrangers, des laboratoires publics ou privés. 


\title{
Green formulation strategy for preparing oil-in-water emulsions via lipase- catalyzed transesterification
}

\author{
Natcha Wongthongdee $^{\mathrm{a}, \mathrm{b}, \mathrm{c}}$, Alain Durand ${ }^{\mathrm{b}, \mathrm{c}}$, Thunyarat Pongtharangkul ${ }^{\mathrm{a}}$, Panya
}

$$
\text { Sunintaboon }^{\mathrm{d}} \text {, Pranee Inprakhon }{ }^{\mathrm{a},}
$$

${ }^{a}$ Department of Biotechnology, Faculty of Science, Mahidol University, Rama VI Rd, Bangkok 10400, Thailand.

${ }^{b}$ Université de Lorraine, Laboratory of Macromolecular Chemical Physics, 1 Rue Grandville, BP 20451, 54001 Nancy, France.

${ }^{c}$ CNRS, Laboratory of Macromolecular Chemical Physics, 1 Rue Grandville, BP 20451, 54001 Nancy, France.

${ }^{d}$ Department of Chemistry, Faculty of Science, Mahidol University, Rama VI Rd, Bangkok 10400, Thailand.

\footnotetext{
* Corresponding author. Tel.: + 6622015311 ; fax: + 6623547160 .

E-mail address: pranee.inp@gmail.com (P. Inprakhon)
} 


\begin{abstract}
Formulation of submicronic diglyceride-in-water emulsions was carried-out without addition of synthetic surfactant in case of commercial caprylic/capric diglyceride. Sugar surfactant was prepared by contacting the oil with a concentrated aqueous solution of sorbitol (70 wt \%) containing lipase AY. Interfacial lipase-catalyzed transesterification took place and led to limited but sufficient amounts of sorbitol ester and monoglyceride, which accumulated in the oil. The enzyme-treated oil could be easily separated from the aqueous phase and used for preparing oil-in-water emulsion without adding any other surfactant. A stable emulsion was obtained for at least 7 days and exhibited better stability at $60{ }^{\circ} \mathrm{C}$ than Tween 20 -stabilized emulsion.
\end{abstract}

Keywords: Sorbitol esters; Lipase; Transesterification; Caprylic/Capric diglyceride; Aqueous biphasic media 


\section{INTRODUCTION}

Surfactants derived from sugar fatty acid esters are attractive ingredients and find many applications in food, pharmaceutical, and cosmetic industries because of their biodegradability, low toxicity, low irritation to eyes and skin and renewable nature of raw materials ${ }^{1-4}$. Pure sugar esters with specific and well controlled structure are difficult to synthesize by standard chemical esterification ${ }^{5-10}$. Enzymatic catalysis associated with mild reaction conditions may provide high selectivity and lead to products with higher purity. However, the loss of catalytic activity of enzymes in some polar solvents, the immiscibility of the reactants, i.e. fatty acid and sugar, are serious difficulties. Tremendous effort has been spent on solving the problem of immiscibility of the substrates. The most common strategies consisted in performing enzymatic reaction either in polar organic solvents (even in mixtures of solvents), in non-conventional media like eutectics or ionic liquids or in heterogeneous reaction media like solid-liquid dispersions. Unfortunately, in all those systems, substrate concentrations remained rather low (less than $0.1 \mathrm{M}$ ), which would be hardly compatible with requirements of most industrial applications. Microemulsions, eutectic melts and biphasic liquid systems were alternative reaction media which helped increasing substrate concentrations because these systems contained mainly sugar and fatty acid. Microemulsion was only applied to the base-catalyzed esterification because of the necessity to perform the reaction at high temperature to maintain the fluidity of the reaction mixture ${ }^{11}$. Lipasecatalyzed esterification in eutectic media resulted in 33-36 times higher overall productivity of sorbitol esters than that obtained in organic media ${ }^{12}$. Nevertheless, the difficulties for media preparation, their high viscosity and the high reaction temperature were significant drawbacks of these processes. Only one study reported lipase-catalyzed esterification in a biphasic liquid medium containing decanoic acid and $70 \mathrm{wt} \%$ sorbitol aqueous solution ${ }^{13}$. Even if oil/water interface could be expected to form a convenient location for catalytic 
activity of lipase, it was impeded by the high concentration of water in the sorbitol phase which resulted in a slow reaction rate and a low acid conversion $(12 \%)$. This represented a significant limitation which could not be compensated by the several benefits offered by this green reaction including high substrate load and absence of harmful reactants.

To the best of our knowledge, most of available literature about lipase-catalyzed synthesis of sugar surfactants attempted to design green manufacturing processes reaching satisfactory performances (yields, rates of production, purity of products...) for large production of surfactants that could be further used as ingredients in various formulations.

In that work we wanted to explore an alternative strategy toward the use of sugar-based surfactants in formulated products. We considered the possibility of designing a formulation process that would include the preparation of the sugar-based surfactants as a unit operation preceding emulsification step. The main interests were to suppress purification operations and to circumvent the problem of low reaction yields by producing just the amount of surfactant required for product formulation. We took the example of the preparation of oil-in-water emulsions stabilized by sorbitol esters. One-step lipase-catalyzed preparation of caprylic/capric diglyceride oil containing limited amounts of sorbitol esters was carried out for the first time in biphasic aqueous medium. The yield and chemical structures of sorbitol esters were investigated in detail using NMR spectroscopy. The resulting oil product containing sorbitol esters was used for formulating caprylic/capric diglyceride-in-water $(\mathrm{O} / \mathrm{W})$ emulsions without any other added surfactant. The droplet size distribution and the shelf life of these emulsions were characterized and compared to control experiments using a synthetic surfactant (Tween 20) or without any surfactant.

\section{EXPERIMENTAL}

\section{Enzyme and chemicals}




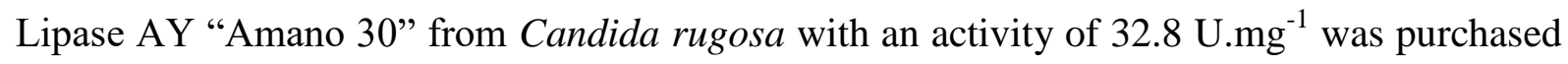
from Amano Enzyme, Japan. Absolute ethanol, chloroform, dichloromethane, D-sorbitol, TLC siliga gel 60 F425 and silica gel $60(0.040-0.063 \mathrm{~mm})$ were purchased from Merck Millipore, Germany. Acetic acid, diethyl ether, dimethyl sulfoxide-d $\mathrm{d}_{6}, \mathrm{n}$-butanol, n-hexane, nile red, sodium bicarbonate, sodium chroride, and sulfuric acid were purchased from SigmaAldrich, UK. Acetonitrile, methanol and formic acid were purchased from Carlo Erba reagents S.p.A., Italy. The Milli-Q purified water was produced using a Milli-Q system (Millipore, USA). Polyoxyethylene (20) sorbitan monolaurate (Tween 20) was purchased from VWR International, Pty Ltd., Australia.

Caprylic/capric diglyceride, a commercial grade of fractioned coconut oil, containing mixed esters of glycerin with caprylic and capric acids, was purchased from Huiles \& Sense, France. The density of the oil sample was experimentally evaluated to 0.98 g.mL ${ }^{-1}$. Analysis of oil sample by LC-MS coupled with ESI analysis provided a value of 372 g.mol ${ }^{-1}$ for the molar mass. ${ }^{1} \mathrm{H}^{13} \mathrm{C}$ NMR analysis (data not shown) based on the triglycerides chemical shift data of previous studies ${ }^{14-16}$ suggested that the oil used in this study was a 50/50 mixture of two caprylic/capric diglycerides isomers.

\section{Transesterification reaction}

One-step caprylic/capric diglyceride transesterification with sorbitol

Experimental conditions were adapted from literature ${ }^{17}$. The reaction mixture containing 1:1 mole ratio of oil to sorbitol, was prepared by mixing $0.32 \mathrm{~g}$ of lipase AY (10,496 U) with 1.34 $\mathrm{g}$ of $70 \% \mathrm{w} / \mathrm{w}$ sorbitol solution (prepared by dissolving $0.94 \mathrm{~g} / 5.16 \mathrm{mmol}$ of sorbitol in 400 $\mu \mathrm{L}$ of water) and $1.92 \mathrm{~g}$ of caprylic/capric diglyceride $(5.16 \mathrm{mmol})$. The mixture initially consisted of two liquid phases. Under a continuous agitation speed of $750 \mathrm{rpm}$ at $45^{\circ} \mathrm{C}$, the reaction mixture turned into light brown turbid. It was visualized by an inverted microscope. 
After $2 \mathrm{~h}$, the reaction mixture was separated into an upper layer of oil and a lower layer of sorbitol solution upon gravity settling for $15 \mathrm{~min}$. The presence of sorbitol esters in both phases was investigated by ${ }^{1} \mathrm{H}$ NMR.

The effect of oil mole ratio was evaluated by varying the amount of caprylic/capric diglyceride added (up to 7.74 and $10.32 \mathrm{mmol}$ ) in the reactor load, keeping 5.16 mole of sorbitol.

\section{Microscopic observation of aqueous biphasic reaction media}

At the beginning and after $4 \mathrm{~h}$, approximately $200 \mu \mathrm{L}$ of reaction mixture (1:1 mole ratio of oil to sorbitol) was sampled and dropped onto a glass slide. Then, the glass cover slip was placed carefully on the top the sample drop and pressed to flatten it. Droplet size distributions were visualized by Olympus BX53 Microscope (Olympus Corporation, Tokyo, Japan) coupled with Olympus cellSens Dimension software Version 1.11 at high power objective $(\times$ 40 Phase contrast Microscopy). The visualization of reaction mixture without enzyme was performed as a negative control. Additionally, the type of emulsion was unambiguously characterized by mixing $10 \mu \mathrm{g}$ of dye nile red thoroughly with $3.18 \mathrm{~g}$ of same reaction mixture at time 0 and $4 \mathrm{~h}$ followed by visualizing with the fluorescence microscope.

\section{Purification and identification of sorbitol caprylate/caprate product}

Twenty-two milliliters of oil phase containing sorbitol caprylate/caprate 0.45 mole/mole of caprylic/capric diglyceride (determined by ${ }^{1} \mathrm{H}$ NMR) was purified by liquid-liquid extraction adapted from literature ${ }^{18}$. Forty four milliliters of dichloromethane were added to oil phase followed by successive washings with $26 \mathrm{~mL}$ of saturated sodium bicarbonate solution $(2: 5$ $\mathrm{v} / \mathrm{v}$ ) two times, three times with $26 \mathrm{~mL}$ of saturated sodium chloride and four times with 60

$\mathrm{mL}$ of Milli-Q purified water in order to completely remove unreacted substrates, side 
products, and salt. A slightly turbid organic phase (lower layer) of each extraction was pooled together and the latter was purified by column chromatography. The presence of sorbitol esters in the eluent was monitored by thin layer chromatography (TLC) ${ }^{5}$. The column was eluted firstly by dichloromethane to get rid of unreacted oil, by dichloromethane: methanol $(95: 5, \quad \mathrm{v} / \mathrm{v})$ to obtain sorbitol diesters $(R f=0.325)$ and finally by dichloromethane/methanol/water $(64 / 10 / 1, \mathrm{v} / \mathrm{v} / \mathrm{v})$ to obtain sorbitol monoester at $R f=0.125$. The separated products were dried under vacuum incubator (BIOBLOCK Scientific co., Ltd., France) at $65{ }^{\circ} \mathrm{C}, 30 \mathrm{mbar}$ for $24 \mathrm{~h}$. The purity of isolated product was estimated by ${ }^{1} \mathrm{H}$ NMR analysis. The degree of substitution and chemical structure were determined by ${ }^{1} \mathrm{H}$ NMR and ${ }^{13}$ C NMR analysis ${ }^{5,18,19}$.

Calculation of conversion and identification of positional substitution using NMR spectroscopy

Spectra were recorded on a Bruker Avance $300 \mathrm{MHz}$ spectrometer using DMSO- $\mathrm{d}_{6}$ as the solvent. The peak assignment was performed on the basis of literature ${ }^{5,19}$ and using a 2D NMR experiment (HSQC, data not shown). All chemical shifts were recorded in $\delta$-units (ppm) relative to ${ }^{1} \mathrm{H}$ residual signal of $\mathrm{DMSO}^{-\mathrm{d}_{6}}(\delta 2.5)$ and relative to ${ }^{13} \mathrm{C}$ residual signal of DMSO-d $_{6}(\delta 39.51)$. For complete assignment see Supporting Information.

The sorbitol caprylate/caprate conversion was calculated using equation (1). $I_{1}$ was the area of the peak at $4.9 \mathrm{ppm}$ (one proton from a hydroxyl group connected to $\mathrm{C} 2$ atom position in sorbitol esters) and $\mathrm{I}_{2}$ was the area of the peak at $5.2 \mathrm{ppm}$ (one proton from $-\mathrm{CH}$ group connected to the secondary carbon atom position on the glycerol backbone of unreacted caprylic/capric diglyceride) $^{14,15}$.

$\%$ conversion $=\left(\frac{I_{1}}{I_{1}+I_{2}}\right) \times 100$ 


\section{Surface tension measurements by du Nouy ring method}

The surface tension in Milli-Q purified water was determined at $25^{\circ} \mathrm{C}$ by du Nouy ring method using FORCE Tensiometer (KRÜSS Gmbh, Germany) as described elsewhere ${ }^{20}$. A series of aqueous solutions $(20 \mathrm{~mL})$ containing various concentrations of sorbitol monoester $\left(2 \times 10^{-8}\right.$ to $\left.2 \times 10^{-2} \mathrm{M}\right)$ were prepared and kept at $25^{\circ} \mathrm{C}$ for $24 \mathrm{~h}$. Measurements were repeated six times and the results were registered as the mean \pm SD.

\section{Kinetics of lipase-catalyzed transesterification reaction}

The reaction conditions at 1:2 mole ratio of sorbitol to caprylic/capric diglyceride were kept for kinetic study. At different reaction times, samples were taken from the upper phase and analyzed by ${ }^{1} \mathrm{H}$ NMR for determining the conversion of caprylic/capric diglyceride. The conversion was monitored as function of time over $4 \mathrm{~h}$. The control reaction without enzyme was also performed.

\section{Emulsion formulation and stability}

The enzymatic reaction was performed for $48 \mathrm{~h}$ to achieve the synthesis of $0.40 \mathrm{~mole} / \mathrm{mole}$ of oil of sorbitol caprylate/caprate in the oil layer. After the oil layer was separated and subsequently formulated into a moisturizing lotion following published procedures ${ }^{21-23}$. A typical procedure consisted of introducing $3.92 \mathrm{~g}$ of caprylic/capric diglyceride containing approximately $40 \%$ of sorbitol esters and $16.08 \mathrm{~g}$ of water to achieve the weight ratio of oil to water $20: 80 \% \mathrm{w} / \mathrm{w}$. The final surfactant concentration was $210.82 \mathrm{mmol} . \mathrm{kg}^{-1}$ emulsion. Twostep emulsification procedure was applied. Firstly, the reaction mixture was mixed by a rotorstator homogenizer (IKA Ultra Turrax T25, IKA Labortechnik, USA) at 110,000 rpm for 2 min. Then, it was mixed by an ultrasonic homogenizer (100 W power, $20 \mathrm{kHz}$ frequency 
range, 50\% of pulsed cycles) equipped with TT 13 probe (SONOPULS HD 2200, BANDELIN electronic GmbH \& Co. KG, Germany) for 2 min in an ice bath. The average droplets size was determined by dynamic light scattering (DLS) (Zetasizer Nano ZS, Malvern Instruments, Malvern, UK) with the refractive index of 1.440 at $25^{\circ} \mathrm{C}$.

The same principle was applied to prepare a moisturizing lotion using Tween 20 as positive control and without any emulsifier as a negative control. The stability of lotions was evaluated by following the variation of the average droplets size over a period of 7 days at 25 ${ }^{\circ} \mathrm{C}$ and $60{ }^{\circ} \mathrm{C}$. Each sample was diluted in distilled water to obtain count rates within the range of 200-300 kcps, which was the experimental suited interval. All results were averages of three measurements.

\section{RESULTS AND DISCUSSION}

\section{Design of formulation process involving lipase-catalyzed synthesis of surfactant}

Caprylic/capric diglyceride, a specific fraction of coconut oil containing medium chain fatty acids (C8 and C10), was chosen as a model substrate since it has been commonly used as emollients in emulsion cosmetic products ${ }^{24,25}$. The commercial oil sample was characterized as a 50/50 mixture of two caprylic/capric diglycerides isomers (see Experimental). In order to prepare oil-in-water emulsions, the common procedure would be to put the oil in contact with an aqueous phase containing a water-soluble surfactant, for instance a sorbitol ester prepared by an enzyme-catalyzed reaction (Figure 1) ${ }^{26-28}$. We designed an alternative procedure where the required amount of surfactant would be synthesized from the oil before the emulsification step. Thus instead of considering enzyme-catalyzed synthesis of surfactant as an industrial operation providing one ingredient for the formulation process, we proposed to include enzyme-catalyzed synthesis as a unit operation of the formulation process itself (Figure 1). To that goal, caprylic/capric diglyceride would be first modified by transesterification with a 
sugar molecule, sorbitol, so as to produce a limited amount of sorbitol ester that would serve as surfactant for the following emulsification step. The reported hydrophilic-lipophilic balance (HLB) of sorbitol ester confirmed that they would be convenient emulsifiers for O/W emulsions $^{29}$. Because of the immiscibility of oil and sorbitol and with the objective of avoiding the use of any organic solvent that would require a supplementary step of extraction, we proposed to carry out the reaction between sorbitol and oil in an aqueous biphasic medium in which a highly concentrated aqueous solution of sorbitol was put in contact with caprylic/capric diglyceride (Figure 2). Preliminary experiments showed that caprylic/capric diglyceride was rather easily dispersed in an aqueous solution of sorbitol.

Enzymes like lipases appeared as convenient catalysts for this reaction since they are known to act at oil/water interfaces ${ }^{30}$ and they have already been used for catalyzing esterifications between sugars and fatty acids in biphasic aqueous media although in a very limited number of studies ${ }^{13,31}$. Lipase AY was used as a catalyst because of higher catalytic activity for esterification of $\mathrm{C} 4, \mathrm{C} 8, \mathrm{C} 10$ and $\mathrm{C} 12$ fatty $\operatorname{acids}^{32}$ and for hydrolysis of triglycerides at $1 / 3$ positions $^{33}$. Moreover, this enzyme exhibits excellent interfacial properties at triglyceride/water interface ${ }^{34}$.

We theorized that previous limitations like low yields evidenced in aqueous biphasic media might be overcome by replacing the fatty acid substrate by the corresponding diglyceride, in other words, by performing enzymatic transesterification instead of esterification. Our assumption was that the catalytic activity of lipase would be increased by using its natural substrates like oils and by suppressing the production of water molecules when changing from esterification to transesterification. In addition the water activity at the interface should be reduced as a result of its lower miscibility with oils as compared to that with fatty acids.

Finally, the recovery of reaction products was considered. The aim was to obtain an accumulation of sorbitol ester in the oil phase so as to recover the mixture of oil and 
surfactant to be used in the emulsification step. Provided that sorbitol ester partitioned in favor of oil phase, the biphasic medium would be separated into an upper oily layer and a lower layer of sorbitol solution by simple gravity settling during $15 \mathrm{~min}$. Our assumption was that the high concentration of sorbitol in the aqueous phase (30 wt $\%$ ) would bring about an accumulation of sorbitol ester in the oily phase by strongly decreasing the solvent quality, in a similar way as the cloud point of nonionic surfactant has been reported to decrease in the

presence of sugars like sorbitol ${ }^{35}$. Preliminary experiments showed that sorbitol ester product was detected only in the oil phase (on the basis of NMR) and that simple gravity settling was enough to obtain two well-separated phases 15 min after stopping stirring biphasic reaction medium.

We concluded that it was possible to prepare caprylic/capric diglyceride containing a limited amount of sorbitol ester by lipase-catalyzed interfacial transesterification and to recover it by simple settling of reaction medium. To the best of our knowledge, this was the first description of such procedure.

\section{One-step caprylic/capric diglyceride transesterification with sorbitol}

We first studied the effect of sorbitol to caprylic/capric diglyceride molar ratio in the reactor load. By varying sorbitol to caprylic/capric diglyceride molar ratio from 1:1 to $1: 2$, the oil conversion decreased from $50 \%$ down to $45 \%$, respectively. The yield of the reaction seemed to be controlled by the extent of emulsification. Indeed, both visual observation and comparison of the times required for a phase separation to occur indicated that an equal molar ratio of sorbitol to oil was more favorable. The reaction medium corresponding to such conditions showed better emulsification of the two phases (fine and stable emulsion). Therefore we deduced that the higher yield obtained was due to the increase of the interfacial area. To the best of our knowledge, this was the first report of the lipase-catalyzed synthesis 
of sorbitol ester in a biphasic system consisting mostly of substrate molecules (oil and sorbitol) with only $13 \%$ of water (used to solubilize sorbitol).

The absence of hydrolysis products was verified by ${ }^{1} \mathrm{H}$ NMR and this result suggested that water did not play its role of nucleophile in this system. This result was attributed to both the decrease of water activity by sorbitol and the exclusion of water molecules from the interface between oil and sorbitol solution.

Reaction medium was sampled after different times and observed with a microscope (Figure 3). Well dispersed droplets could be observed in the reaction mixture, especially after adding the biocatalyst. These droplets appeared as gold fluorescence after staining with Nile red (a fluorescence dye generally selected for the detection of lipid droplets by fluorescence microscopy) which confirmed the formation of an $\mathrm{O} / \mathrm{W}$ emulsion ${ }^{36,37}$. Mean droplet diameters as estimated from the fluorescence microscopic images were approximately the same range either in the absence $(5.3 \pm 2.7 \mu \mathrm{m})$ or in the presence of lipase $(5.0 \pm 2 \mu \mathrm{m}$ and $4.5 \pm 1.9$ $\mu \mathrm{m})$. In contrast, the particle density of the reaction mixture without enzyme was significantly lower than that observed after adding the biocatalyst at $0 \mathrm{~h}$ (Figure 3b). Apart from catalyzing the transesterification, lipase was also involved in stabilizing the oil droplets through its adsorption at the oil/water interface. During the control experiment without lipase, the biphasic medium remained nearly transparent very limited dispersion of oil droplets into the aqueous sorbitol solution (Figure 3a, left inset). Lipase acted as both stabilizer and catalyst of transesterification, which had been already used for lipase-catalyzed polymerization in aqueous dispersion ${ }^{38}$.

All raw materials (caprylic/capric diglyceride, sorbitol, water and lipase AY) were safe and renewable ${ }^{39-43}$. In addition, the reaction mixture contained only reactants, catalyst and water, i.e. the minimum compounds. 
In addition, the lipase-catalyzed transesterification of caprylic/capric diglyceride produced not only the sorbitol esters surfactant, but also another important class of biosurfactants i.e. monoglycerides ${ }^{30}$. Thus, it was not necessary to reach high conversion of oil to sorbitol esters since the goal of the reaction was to produce enough surfactant molecules to stabilize the targeted oil-in-water emulsion. All obtained products partitioned mainly in the oil phase and therefore could be simply separated from sorbitol solution and enzyme by gravity settling. Moreover, the treated oil phase exhibited the same color and transparency as the original oil phase (Figure 3c, left inset). Finally enzymatic reaction was carried out under mild reaction condition (at $45^{\circ} \mathrm{C}$ ) which was also a significant advantage.

The purification of reaction products was designed and carried out so as to get insight into the chemical structure of sorbitol esters and positional selectivity of enzyme catalysis in biphasic aqueous medium.

\section{Product purification and characterization}

The oil layer of a reaction mixture with $45 \%$ conversion of oil to sorbitol ester (as determined by ${ }^{1} \mathrm{H}$ NMR) was further purified by column chromatography. The TLC plate revealed three spots with the $R f$ of $0.36,0.33$, and 0.22 which were attributed to sorbitol di- and triesters ${ }^{5}$. The spot at $R f$ of 0.125 was attributed to sorbitol monoesters. In total, $38.36 \%$ of sorbitol esters could be purified from the crude oil layer with sorbitol polyesters as the main product (87\% yield of the total obtained sorbitol esters).

The structure of sorbitol esters was characterized by ${ }^{1} \mathrm{H}$ NMR (see Experimental) according to litterature ${ }^{5}$. The signals of the six carbons atoms of the sorbitol moiety $(59.757$ ppm to 75.344 ppm) consisting of two primary carbons (at C5 and C6) and four secondary carbons (at C1, $\mathrm{C} 2, \mathrm{C} 3$, and C4) were distinguished by the J-modulated spin-echo ${ }^{13} \mathrm{C}$ NMR spectroscopy for 
the differentiation of ${ }^{13} \mathrm{C}$ signals of $-\mathrm{CH},-\mathrm{CH}_{2},-\mathrm{CH}_{3}$ groups and quaternary carbons (Figure $4)^{44}$.

The acyl substitutions on these carbons were identified by ${ }^{13} \mathrm{C}$ NMR (Figure 4). According to previous studies, the acylation of hydroxyl groups of sugar/sugar alcohol moiety resulted in a downfield shift of the peak corresponding to the $O$-acylated carbon and an upfield shift of the peak corresponding to the neighboring carbons ${ }^{5,45,46}$. Based on this knowledge and a bidimensional NMR experiment $\left({ }^{1} \mathrm{H}^{-13} \mathrm{C}\right.$ HSQC, data not shown), it was found that caprylate/caprate were substituted on the primary carbons (C5 and C6) of the sorbitol moiety. The signals from the mixture of two positional isomers of sorbitol monocaprylate/caprate from the C5 isomer (substitution of caprylate/caprate on C5) and the C6 isomer (substitution of caprylate/caprate on C6) were evidenced on spectra (Figure 4). For the C5 isomer, the signal of substituted C5 (C5-S5) shifted downfield at $66.391 \mathrm{ppm}$, the C1 neighboring carbon (C1-S5) shifted upfield at $70.689 \mathrm{ppm}$, while the other non-substituted carbons of sorbitol moiety remained unchanged. In case of the C6 isomer, the substitution of C6 resulted in a downfield shift of C6 (C6-S6) at 65.637 ppm, an upfield shift of C2 (C2-S6) at 69.320 ppm and no shift of $\mathrm{C} 1, \mathrm{C} 3, \mathrm{C} 4$ and $\mathrm{C} 5$. No effect of fatty acid chain on the resonance of substituted carbons could be observed with ${ }^{13} \mathrm{C}$ NMR data.

The modification of sorbitol generally led to a complex mixture of regioisomers due to the number of hydroxyl groups. The use of oil composed of different fatty acid chains (C8 and C10) even increased the number of possible regioisomers. Thus, an identification of positional substitution of sorbitol polycaprylate/caprate was delicate. Based on HSQC data (data not shown), it was found that the sorbitol diesters were substituted on primary carbons (C5 or C6) and on one secondary carbon $(\mathrm{C} 1)$ of the sorbitol moiety. This result agreed with previous works about the substitution pattern toward the secondary hydroxyl group in the carbohydrate moiety when the catalysis by lipase from Candida rugosa ${ }^{47}$ and from Candida antarctica ${ }^{5}$ 
was used in the synthesis of carbohydrates fatty acid esters-based biosurfactant in solvent media. Mixture of two positional sorbitol dicaprylate/caprate isomers was evidenced (Figure 4, lower figure). Signals from the C5-C6 isomer (substitution of dicaprylate/caprate on C5 and C6) and the C1-C5 isomer (substitution of dicaprylate/caprate on the C1 and C5) were identified. For the C5-C6 isomer, the signal of substituted C5 (C5-S5) and C6 (C6-S6) shifted downfield at $66.249 \mathrm{ppm}$ and 65.584-65.451 ppm, respectively. The $\mathrm{C} 1$ and $\mathrm{C} 2$ neighboring carbons (C1-S5, C2-S6) shifted upfield at 70.885-70.543 ppm and 69.276-69.105 ppm. The other non-substituted carbons $(\mathrm{C} 3, \mathrm{C} 4)$ of sorbitol moiety remained unchanged. In case of the C1-C5 isomer, the substitution of $\mathrm{C} 1$ resulted in a downfield shift of $\mathrm{C} 1$ (C1-S1) at 75.344 ppm, an upfield shift of C5 (C5-S1) at 59.757 ppm, and no shift of C4 and C6. The upfield shift of another neighboring carbon C3 (C3-S1) was difficult to observe because of overlapping with the peak from C2-S6 or C4.

In this study, lipase AY showed the selectivity toward the primary hydroxyl groups of sorbitol moiety similar to that reported previously ${ }^{5,27}$. Thus, these results demonstrated that the position of alkyl substitution was not affected by the use of an aqueous biphasic reaction medium as compared to organic solvent. Moreover, the acylation at the secondary hydroxyl group of the sorbitol moiety was shown to occur.

Interestingly, previous work showed that the selectivity toward fatty acid chain length was similar for caprylic and capric fatty acid $\operatorname{chain}^{32}$. As a conclusion, the mixture of sorbitol esters synthesized by lipase AY-catalyzed transesterification of sorbitol and caprylic/capric diglyceride was limited to the sorbitol mono- and diester, in which the caprylic and capric fatty acid chains were distributed between $\mathrm{C} 5, \mathrm{C} 6$, and/or C1 positions.

\section{Surface tension and critical micelle concentration of purified surfactants}


The surfactant properties of sorbitol monoesters extracted and purified from reaction medium were characterized (Table 1): critical micelle concentration $\left(C M C\right.$ in mol. $\left.\mathrm{L}^{-1}\right)$, molar excess at interface $\left(\Gamma\right.$ in mol. $\left.\mathrm{m}^{-2}\right)$ and effectiveness i.e. minimum value of surface tension of surfactant solutions $\left(\gamma_{\min } \text { in } \mathrm{mN} \cdot \mathrm{m}^{-1}\right)^{20,48}$

The content of caprylic fatty acid chain content was expected to be higher than capric fatty acid chain, on the basis of fatty acid composition of oil (caprylic acid 57\%/capric acid $40 \%$ in mole) and the same specificity of lipase AY for both acids. Surfactant characteristics were found consistent with those reported for other sorbitol monoesters synthesized by enzymecatalyzed esterification in organic solvent (Table 1).

\section{Kinetic study as a tool for tuning the amount of sorbitol esters in caprylic/capric diglyceride}

Kinetic study of enzyme catalyzed transesterification was carried out so as to adjust the amount of sorbitol esters present in the oil by controlling the time let for reaction before the use for formulation. The ease of phase separation between oil and aqueous solution of sorbitol strongly facilitated the kinetic study. The mole ratio of sorbitol to oil was 1:2. At specific time of reaction, the oil phase was sampled immediately after stopping the agitation and the conversion percentage was analyzed by ${ }^{1} \mathrm{H}$ NMR. A control experiment without addition of enzyme was carried out during $4 \mathrm{~h}$ (Figure 1S in Supporting Information).

A limited amount of sorbitol ester was produced by non catalyzed reaction (ca. $0.3 \mathrm{M})$. The maximum conversion to ester was reached within 30 minutes with a maximum sorbitol caprylate/caprate concentration equal to $1.309 \pm 0.022 \mathrm{M}$ (ca. 580.48 g. $\mathrm{L}^{-1}$ ). The experiment was repeatable and the rather fast reaction course suggested that lower enzyme loads may be used. However this parameter was not investigated in this study. On the basis of the slope of the first part of the curve the productivity was estimated around $2.76 \mathrm{~mol} \cdot \mathrm{L}^{-1} \cdot \mathrm{h}^{-1}$. 
Comparing with two-phase reaction media, the improvement of 4.65 time in maximum conversion $(0.121 \mathrm{~mole} / \mathrm{mole}$ of fatty acid $)$ and 200 times in productivity $\left(0.014 \mathrm{~mol} . \mathrm{L}^{-1} \cdot \mathrm{h}^{-1}\right)$ was obtained. Regarding the comparison with esterification in the eutectic media, the productivity of biphasic system without any optimization $\left(2.76 \mathrm{~mol} \cdot \mathrm{L}^{-1} \cdot \mathrm{h}^{-1}\right)$ was only 2 times lower than that obtained in the eutectic media $\left(6.0 \mathrm{~mol} \cdot \mathrm{L}^{-1} \cdot \mathrm{h}^{-1}\right)$. Moreover, it was found that our reaction system reached the equilibrium within $30 \mathrm{~min}$ while according to the previous works it needed 300 hours. This was an evident advantage of doing the reaction in a biphasic media. Besides high substrate concentrations, in addition a very fast rate as a result of an increase of activity of lipases at interfaces had been often observed. Our assumption was that caprylic/capric diglyceride had at least two favorable characteristics as an acyl donor; lower surface tension and more hydrophobic interface than capric acid. Indeed, the biphasic reaction medium of caprylic/capric diglyceride had more available interface and more favorable hydrophobic interface for lipases catalysis ${ }^{49}$.

The interfacial transesterification of the caprylic/capric diglyceride led to contents around 45$50 \% \mathrm{w} / \mathrm{w}$ sorbitol caprylate/caprate (conversion yield of $0.41 \mathrm{~mole} / \mathrm{mole}$ of caprylic/capric diglyceride), i.e. in the same range as emulsifiers in cosmetic products ${ }^{21,22,50,51}$.

\section{Preparation and shelf life of emulsions using pre-treated oil}

The emulsifying ability of sorbitol caprylate/caprate and the shelf life of corresponding O/W emulsions were investigated. A model cosmetic $\mathrm{O} / \mathrm{W}$ emulsion was prepared according to a formula of a standard moisturing lotion using either enzyme treated oil or Tween 20 at concentrations of 8.75 and $20.56 \% \mathrm{w} / \mathrm{w}$ emulsion, respectively $\left(210.82 \mathrm{mmol} . \mathrm{kg}^{-1}\right.$ of emulsion). Both visual observation and DLS experiments clearly evidenced that the emulsions containing surfactants were finer and more uniform in size than control without surfactants. Indeed, the average oil droplets size of emulsion without emulsifier could not be determined 
by DLS due to macroscopic phase separation as indicated by a very high PDI $(>0.5)$. In the presence of an emulsifier, the PDI of emulsions were much lower and in the generally accepted range of monomodal narrow size distributions $(<0.2)$. The emulsion containing sorbitol esters showed significantly higher average oil droplet diameter $(324 \pm 12 \mathrm{~nm}, \mathrm{PDI}=$ 0.16) than that containing Tween $20(166 \pm 14 \mathrm{~nm}$, PDI $=0.19)$. The colloidal characteristics of the emulsion prepared using enzyme treated oil confirmed its good emulsifying ability without any purification step needed.

For both emulsions, the average droplet diameter remained almost unchanged during storage for 7 days at $25{ }^{\circ} \mathrm{C}$ (Figure 5). However, when the stability test was prolonged to 120 days, a macroscopic phase separation was observed in the emulsion prepared with Tween 20 while no oiling off could be detected with the emulsion prepared with enzyme treated caprylic/capric diglyceride. Finally, when storage temperature was increased from $25{ }^{\circ} \mathrm{C}$ to $60{ }^{\circ} \mathrm{C}$, no significant variation of average droplet diameter could be detected for the emulsion prepared with enzyme treated oil, contrary to the one prepared with Tween 20 (Figure 5). This was consistent with the well-know low temperature sensitivity of sugar surfactants.

The good storage stability of emulsion prepared with enzyme treated oil could be attributed to the simultaneous presence of sorbitol esters and monoglycerides both resulting from lipasecatalyzed transesterification. Such synergistic effect has already been evidenced ${ }^{52}$. Furthermore, glyceryl monocaprylate/caprate showed human skin penetration enhancing effect and was a mild, safe, and well-tolerated skin penetration enhancer in topical pharmaceutical and cosmetic formulations ${ }^{53}$. Thus the strategy of enzyme treatment of oil before emulsion formulation appeared promising by considering both colloidal characteristics and end use properties. 


\section{CONCLUSIONS}

Lipase-catalyzed transesterification of sorbitol and caprylic/capric diglyceride allowed the direct synthesis of sorbitol caprylate/caprate in aqueous biphasic medium. This green, and efficient procedure was completely chemical solvent free and toxic catalyst free. Enzymatically synthesized biosurfactant exhibited an excellent emulsifying ability incorporated with a side product such as monoglyceride derived from the reaction media by providing a rather uniform and stable cosmetic emulsion after long-term storage. The present work established a green manufacturing protocol for the ready-to-use caprylic/capric diglyceride blended with sorbitol esters emulsifier, which was suitable for organic cosmetics and fostering sustainability in the beauty industry.

At present, an optimization of the reaction mixture in order to increase the rate and productivity, a reuse of aqueous sorbitol phase containing lipases and the extension of this enzymatic technique to other natural oils are in progress in our laboratory.

\section{Acknowledgements}

This work was financially supported by the Royal Golden Jubilee Ph.D. Program, Thailand Research Fund, Mahidol University, French Embassy in Thailand [grant number PHD/0161/2554], CNRS and Université de Lorraine, France. 


\section{References}

(1) Ayala-Bravo, H. A.; Quintanar-Guerrero, D.; Naik, A.; Kalia, Y. N.; Cornejo-Bravo, J. M.; Ganem-Quintanar, A. Effects of Sucrose Oleate and Sucrose Laureate on in Vivo Human Stratum Corneum Permeability. Pharm. Res. 2003, 20, 1267-1273.

(2) Klekner, V.; Kosaric, N. Biosurfactants for cosmetics. Surfactant Sci. Ser. 1993, 48, 373-389.

(3) Wang, X.; Miao, S.; Wang, P.; Zhang, S. Highly efficient synthesis of sucrose monolaurate by alkaline protease Protex 6L. Bioresource Technol. 2012, 109, 7-12.

(4) Allen, D. K.; Tao, B. Y. Carbohydrate-Alkyl Ester Derivatives as Biosurfactants. J. Surfact. Deterg. 1999, 2, 383-390.

(5) Ducret, A.; Giroux, A.; Trani, M.; Lortie, R. Enzymatic Preparation of Biosurfactants from Sugars or Sugar Alcohols and Fatty Acids in Organic Media Under Reduced Pressure. Biotechnol. Bioeng. 1995, 48, 214-221.

(6) Eggleston, G.; Vercellotti, J. R. Degradation of Sucrose, Glucose and Fructose in Concentrated Aqueous Solutions Under Constant pH Conditions at Elevated Temperature. $J$. Carbohydr. Chem. 2000, 19, 1305-1318.

(7) Hass, H. B.; Summit, N. J.; Snell, F. D.; York, W. C.; Osipow, L. I. 1959. USA Patent No. 2,893,990.

(8) Khan, N. R.; Rathod, V. K. Enzyme catalyzed synthesis of cosmetic esters and its intensification: A review. Process Biochem. 2015, 50, 1793-1806.

(9) Stockburger, G. J. US4297290A, 1981.

(10) Van, L. F. WO2004058671 A1, 2004.

(11) Osipow, L. I.; Rosenblatt, W. Micro-Emulsion Process for the Preparation of Sucrose Esters J. Am. Oil Chem. Soc. 1967, 44, 307-309. 
(12) Kim, H. J.; Youn, S. H.; Shin, C. S. Lipase-catalyzed synthesis of sorbitol-fatty acid esters at extremely high substrate concentrations. J. Biotechnol. 2006, 123, 174-184.

(13) Janssen, A. E. M.; Lefferts, A. G.; van't Riet, K. Enzymatic synthesis of carbohydrate esters in aqueous media. Biotechnol. Lett. 1990, 12, 711-716.

(14) Boulos, Z.; Duceppe, J. S.; Penney, C. 2013. Patent No. WO 2013126990 A1.Prometic Biosciences Inc.

(15) Lie Ken Jie, M. S. F.; Lam, C. C. 1H-Nuclear magnetic resonance spectroscopic studies of saturated, acetylenic and ethylenic triacylglycerols. Chem. Phys. Lipids 1995, 77, $155-171$.

(16) Lie Ken Jie, M. S. F.; Lam, C. C. 13C-Nuclear magnetic resonance spectroscopic studies of triacylglycerols of type AAA containing (Z)-and (E)-monoethylenic acyl groups. Chem. Phys. Lipids 1995, 78, 15-27.

(17) Khan, N. R.; Jadhav, S. V.; Rathod, V. K. Lipase catalysed synthesis of cetyl oleate using ultrasound: Optimisation and kinetic studies. Ultrason. Sonochem. 2015, 27, 522-529. (18) Wei, W.; Feng, F.; Perez, B.; Dong, M.; Guo, Z. Biocatalytic synthesis of ultra-longchain fatty acid sugar alcohol monoesters. Green Chem. 2015, 17, 3475-3489.

(19) Chung, H.-Y.; Park, J.; Kim, J.-H.; Kong, U.-Y. Preparation of Sorbitol Fatty Acid Polyesters, Potential Fat Substitutes: Optimization of Reaction Conditions by Response Surface Methodology. J. Am. Oil Chem. Soc. 1996, 73, 637-643.

(20) Ducret, A.; Giroux, A.; Trani, M.; Lortie, R. Characterization of Enzymatically Prepared Biosurfactants. J. Am. Oil Chem. Soc. 1996, 73, 109-113.

(21) Inc., L. A. M. Fast absorbing facial moisturizing cream. http://www.lubrizol.com/PersonalCare/Formulations/F-0094\%28AP\%29-Fast-AbsorbingFacial-Moisturizing-Cream.html (September 15, 2015), 
(22) Garden, N. s. Nature's garden recipe.

http://www.naturesgardencandles.com/item/00roslot/rose-lotion-recipe/1.html (January 2, 2016),

(23) Piao, J.; Adachi, S. Stability of O/W emulsions prepared using various monoacyl sugar alcohols as an emulsifier. Innovative Food Sci. Emerging Technol. 2006, 7, 211-216. (24) Zhang, F.; Proctor, A. Rheology and Stability of Phospholipid-Stabilized Emulsions. J. Am. Oil Chem. Soc. 1997, 74, 869-874.

(25) Marcato, B.; Guerra, S.; Vianello, M.; Scalia, S. Migration of antioxidant additives from various polyolefinic plastics into oleaginous vehicles. Int. J. Pharm. 2003, 257, 217-225. (26) Gulati, R.; Saxena, R. K.; Gupta, R.; Yadav, R. P.; Davidson, W. S. Parametric optimisation of Aspergillus terreus lipase production and its potential in ester synthesis. Process Biochem. 1999, 35, 459-464.

(27) Gulati, R.; Arya, P.; Malhotra, B.; Prasad, A. K.; Saxena, R. K.; Kumar, J.; Watterson, A. C.; Parmar, V. S. Novel biocatalytic esterification reactions on fatty acids: synthesis of sorbitol 1(6) - monostearate. ARKIVOC (iii) 2003, 159-170.

(28) Yadav, R. P.; Saxena, R. K.; Gupta, R.; Davidson, W. S. Production of biosurfactant from sugar alcohols and natural triglycerides by Aspergillus terreus lipase J. Sci. Ind. Res. 1997, 56, 479-482.

(29) Zhang, X.; Nie, K.; Zheng, Y.; Wang, F.; Deng, L.; Tan, T. Enzymatic production and functional characterization of D-sorbitol monoesters with various fatty acids. Catalysis Commun. 2015, 72, 138-141.

(30) Reis, P.; Holmberg, K.; Watzke, H.; Leser, M. E.; Miller, R. Lipases at interfaces: A review. Adv. Colloid Interface Sci. 2009, 147-148, 237-250. 
(31) Seino, H.; Uchibori, T.; Nishitani, T.; Inamasu, S. Enzymatic Synthesis of Carbohydrate Esters of Fatty Acid (I) Esterification of Sucrose, Glucose, Fructose and Sorbitol. J. Am. Oil Chem. Soc. 1984, 61, 1761-1765.

(32) Janssen, A. E. M.; Vaidya, A. M.; Halling, P. J. Substrate specificity and kinetics of Candida rugosa lipase in organic media. Enzyme Microbiol. Technol. 1996, 18, 340-346. (33) Rogalska, E.; Cudrey, C.; Ferrato, F.; Verger, R. Stereoselective Hydrolysis of Triglycerides by Animal and Microbial Lipases. Chirality 1993, 5, 24-30.

(34) Lotti, M.; Tramontano, A.; Longhi, S.; Fusetti, F.; Brocca, S.; Pizzi, E.; Alberghina, L. Variability within the Candida rugosa Upases family. Protein Eng. 1994, 7, 531-535.

(35) Khan, M. B.; Hoque, M. A.; Islam, D. M. S. Physicochemical investigation of the clouding behavior and thermodynamics of p-tert-alkylphenoxy poly (oxyethylene) ether micelles in aqueous environment and in the presence of diols. J. Chem. Thermodynamics 2015, 89, 177-182.

(36) Greenspan, P.; Mayer, E. P.; Fowler, S. D. Nile Red: A Selective Fluorescent Stain for Intracellular Lipid Droplets J. Cell Biol. 1985, 100, 965-973.

(37) Selvarajan, R.; Felföldi, T.; Tauber, T.; Sanniyasi, E.; Sibanda, T.; Tekere, M. Screening and Evaluation of Some Green Algal Strains (Chlorophyceae) Isolated from Freshwater and Soda Lakes for Biofuel Production. Energies 2015, 8, 7502-7521.

(38) Panlawan, P.; Luangthongkam, P.; Wiemann, L. O.; Sieber, V.; Marie, E.; Durand, A.; Inprakhon, P. Lipase-catalyzed interfacial polymerization of $\omega$-pentadecalactone in aqueous biphasic medium: A mechanistic study. J. Mol. Catal. B Enzym. 2013, 88, 69-76.

(39) Bergfeld, W. F.; Belsito, D. V.; Klaassen, C. D.; Marks, J. G.; Shank, R. C.; Slaga, T. J.; Snyder, P. W.; Andersen, F. A.; Diamante, C. Final report on the safety assessment of amended safety assessment of Cocos Nucifera (coconut) oil, coconut acid, hydrogenated coconut acid, hydrogenated coconut oil, ammonium cocomonoglyceride sulfate, butylene 
glycol cocoate, caprylic/capric/coco glycerides, cocoglycerides, coconut Alcohol, coconut oil decyl esters, decyl cocoate, ethylhexyl cocoate, hydrogenated coco-glycerides, isodecyl cocoate, lauryl cocoate, magnesium cocoate, methyl cocoate, octyldodecyl cocoate, pentaerythrityl cocoate, potassium cocoate, potassium hydrogenated cocoate, sodium cocoate, sodium cocomonoglyceride sulfate, sodium hydrogenated cocoate, and tridecyl cocoate. Cosmet. Ingredient Rev. 2008, 1-31.

(40) Flood, M. T.; Kondo, M. Safety Evaluation of Lipase Produced from Candida rugosa: Summary of Toxicological Data. Reg. Toxicol. Pharmacol. 2001, 33, 157-164.

(41) Administration, F. a. D.

http://www.fda.gov/downloads/Food/.../GRAS/NoticeInventory/UCM266653 (May 6, 2016), (42) Rulis, A. M. Agency Response Letter GRAS Notice No. GRN 000081.

http://www.fda.gov/Food/IngredientsPackagingLabeling/GRAS/NoticeInventory/ucm154591. htm (May 6, 2016),

(43) Becker, L. C.; Bergfeld, W. F.; Belsito, D. V.; Hill, R. A.; Klaassen, C. D.; Marks Jr, J. G.; Shank, R. C.; Slaga, T. J.; Snyder, P. W.; Andersen, F. A. Final Report of the Amended Safety Assessment of Myristic Acid and Its Salts and Esters as Used in Cosmetics. Int. J. Toxicology 2010, 29, 162S-186S.

(44) Hesse, M.; Meier, M.; Zeeh, B., Spectroscopic methods in organic chemistry. $2^{\text {nd }}$ ed.; Thieme Publishing Group: Stuttgart, 2007.

(45) Ferreira, L.; Gil, M. H.; Dordick, J. S. Enzymatic synthesis of dextran-containing hydrogels. Biomaterials 2002, 23, 3957-3967.

(46) Kitagawa, M.; Fan, H.; Raku, T.; Shibatani, S.; Maekawa, Y.; Hiraguri, Y.; Kurane, R.; Tokiwa, Y. Selective enzymatic preparation of vinyl sugar esters using DMSO as a denaturing co-solvent. Biotechnol. Lett. 1999, 21, 355-359. 
(47) Kaewprapan, K.; Tuchinda, P.; Marie, E.; Durand, A.; Inprakhon, P. pH-imprinted lipase catalyzed synthesis of dextran fatty acid ester. J. Mol. Catal. B Enzym. 2007, 47, 135142.

(48) Zhang, X.; Song, F.; Taxipalati, M.; Wei, W.; Feng, F. Comparative Study of SurfaceActive Properties and Antimicrobial Activities of Disaccharide Monoesters. PLoS ONE 2014, 9, e114845.

(49) Chumpitaz, L. D. A.; Coutinho, L. F.; Meirelles, A. J. A. Surface Tension of Fatty Acids and Triglycerides. J. Am. Oil Chem. Soc. 1999, 76, 379-382.

(50) Midkiff, R. How to make creams and lotions. Making lotions and creams instructions. http://www.diycosmetics.com/pages/How-to-Make-Creams-and-Lotions.html (January 2, 2016),

(51) Murphy, M. P.; Smith, R. A. J.; Taylor, K. M. EP2271349 A1, 2011.

(52) Yaghmur, A.; Aserin, A.; Mizrahi, Y.; Nerd, A.; Garti, N. Argan Oil-In-Water Emulsions: Preparation and Stabilization. J. Am. Oil Chem. Soc. 1999, 76, 15-18.

(53) Cornwell, P. A.; Tubek, J.; van Gompel, H. A. H. P.; Little, C. J.; Wiechers, J. W. Glyceryl monocaprylate:caprate as a moderate skin penetration enhancer. Int. J. Pharm. 1998, $171,243-255$. 
Table 1: Surface active properties of sorbitol monoesters at air/water interface (for definitions see text).

\begin{tabular}{|c|c|c|c|c|}
\hline Sorbitol monoester & $C M C\left(\mathrm{~mol} . \mathrm{L}^{-1}\right)$ & $\gamma_{\min }\left(\mathrm{mN} \cdot \mathrm{m}^{-1}\right)$ & $\Gamma\left(\mathrm{mol} . \mathrm{m}^{-2}\right)$ & Reference \\
\hline Caprylate & $12 \times 10^{-3}$ & 26.3 & --- & 20 \\
\hline Caprylate/caprate & $2 \times 10^{-3}$ & 22.5 & $2.5 \times 10^{-6}$ & This work \\
\hline Laurate & $0.25 \times 10^{-3}$ & 29.4 & --- & 20 \\
\hline
\end{tabular}




\section{Figure Captions}

Figure 1: Principle of formulation process including (bottom) or not including (top) the enzyme catalyzed synthesis of sugar surfactant.

Figure 2: Proposed green formulation process involving lipase-catalyzed transesterification.

Figure 3: Microscopic images ( $\mathrm{x}$ 40, phase contrast (left figure) and fluorescence (right figure) microscopy) of reaction mixture (a) without enzyme at $0 \mathrm{~h}$ (b) with enzyme at $0 \mathrm{~h}$ and (c) with enzyme at $4 \mathrm{~h}$. Insets of left figure represent the corresponding reaction mixture after 1 min gravity settling.

Figure 4: J-modulated ${ }^{13} \mathrm{C}$ NMR spectrums of sorbitol monocaprylate/monocaprate isomers (upper), and sorbitol dicaprylate/caprate isomers (lower).

Figure 5: Average droplet diameter $(\mathrm{nm})$ determined by DLS of emulsions containing sorbitol caprylate/caprate (diamonds) and Tween 20 (triangles) stored at $25{ }^{\circ} \mathrm{C}(-)$ and $60{ }^{\circ} \mathrm{C}$ (--) over 0-7 days. Emulsion prepared with Tween 20 and stored at $60{ }^{\circ} \mathrm{C}$ was no longer characterized after 3 days because of phase separation. 
Figure 1
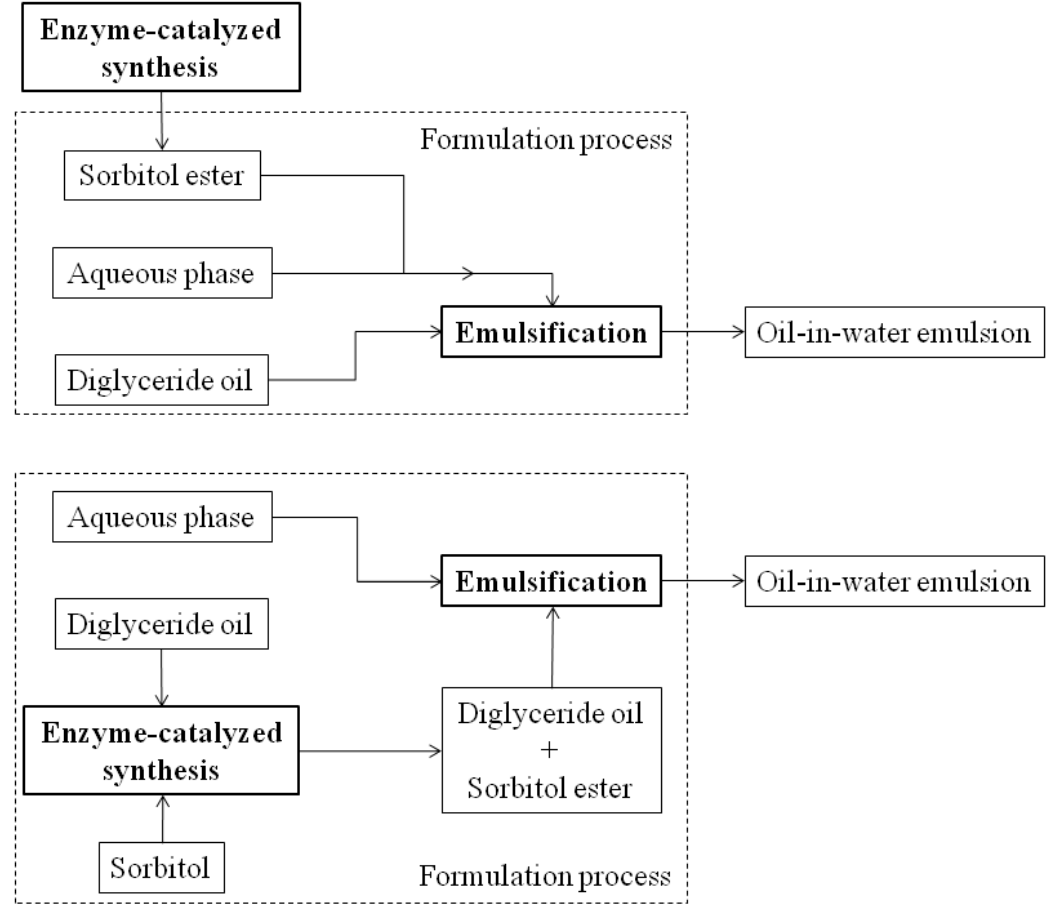
Figure 2

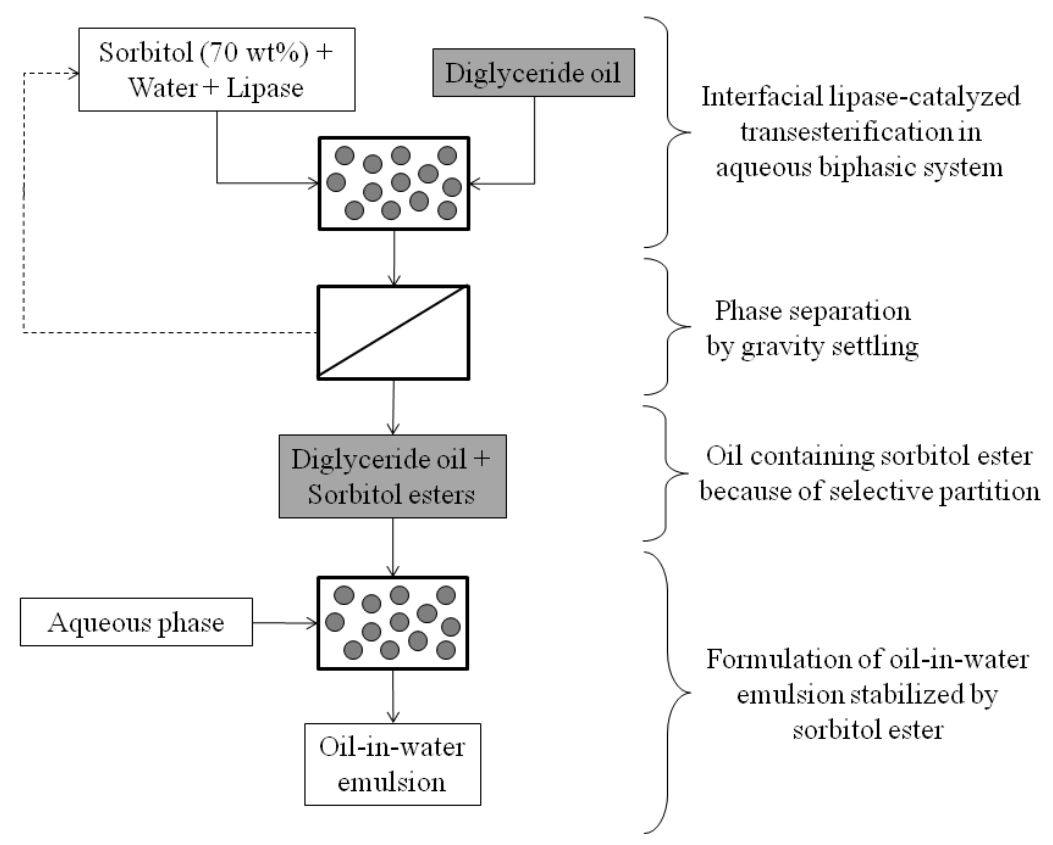


Figure 3

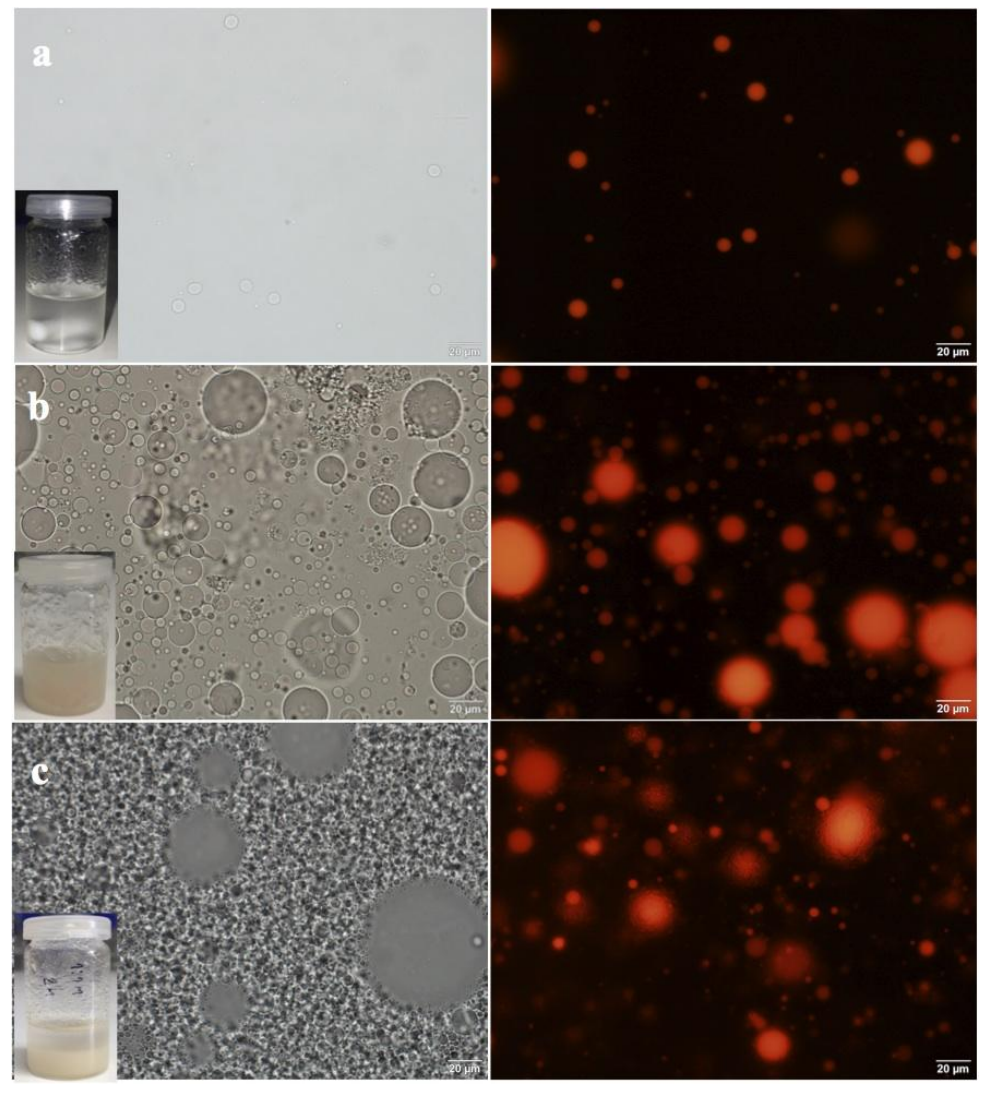


Figure 4

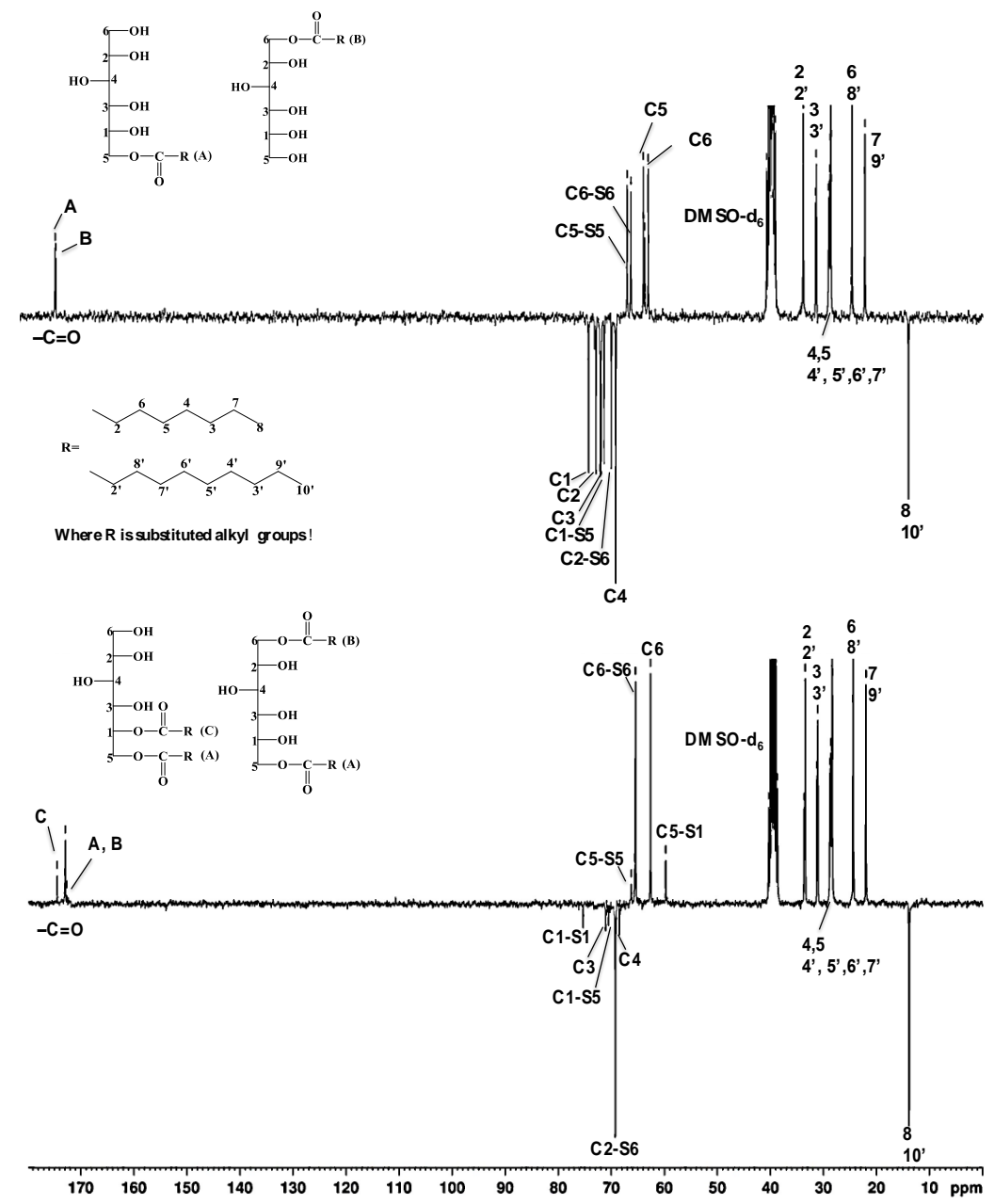


Figure 5

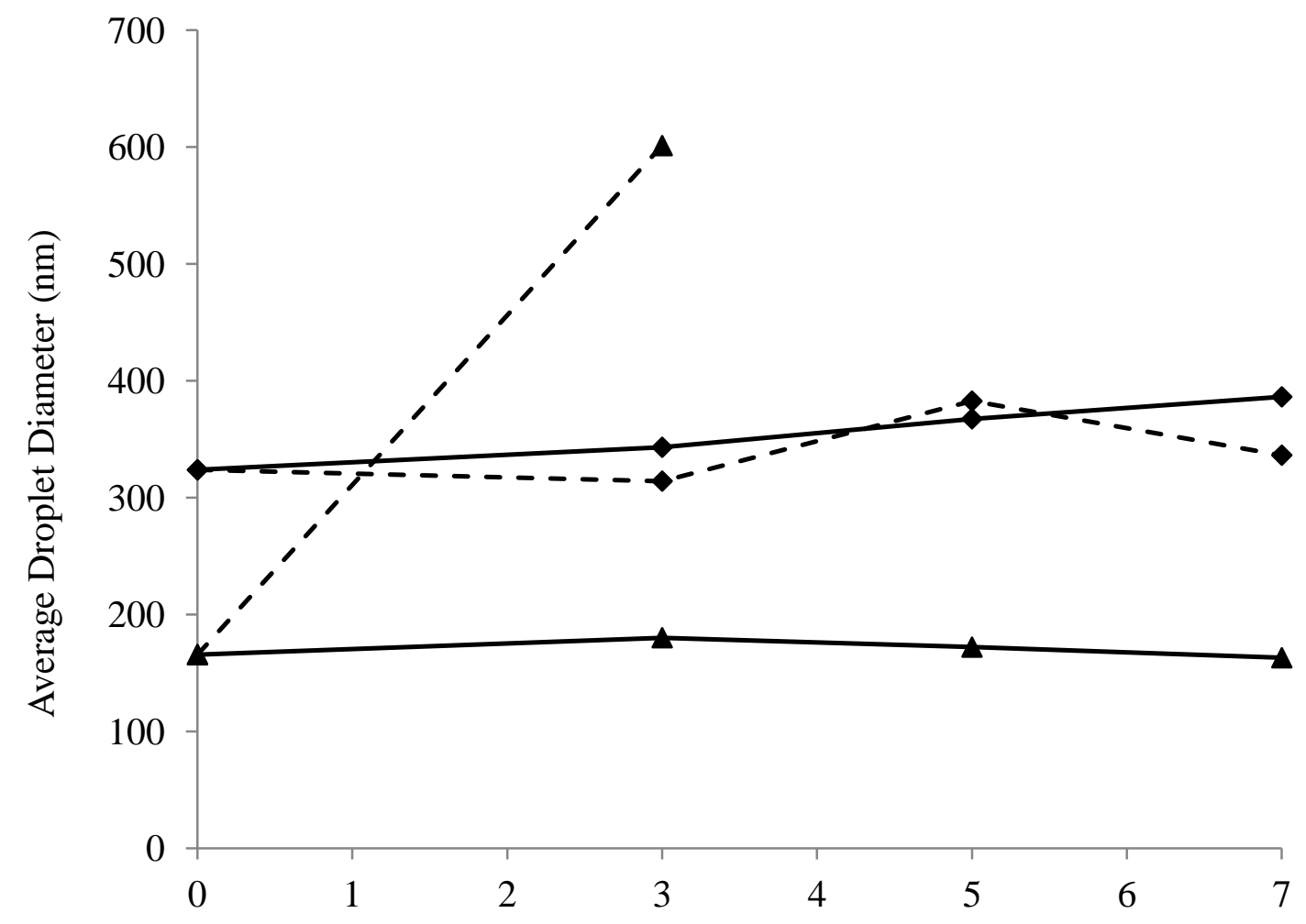

Storage time (Day) 


\section{Supporting Information}

Peak assignment for sorbitol monocaprylate/caprate and sorbitol dicaprylate/caprate in ${ }^{1} \mathrm{H}$ NMR and ${ }^{13} \mathrm{C}$ NMR; and sorbitol caprylate/caprate concentration vs. reaction time after 0-4 $\mathrm{h}$ with and without lipase. 


\section{For Table of Contents Use Only}

Green formulation strategy for preparing oil-in-water emulsions via lipase-

\section{catalyzed transesterification}

Natcha Wongthongdee, Alain Durand, Thunyarat Pongtharangkul, Panya

Sunintaboon, Pranee Inprakhon

A green formulation strategy was proposed for $\mathrm{O} / \mathrm{W}$ emulsions involving enzymecatalyzed synthesis of surfactant immediately before emulsification step.

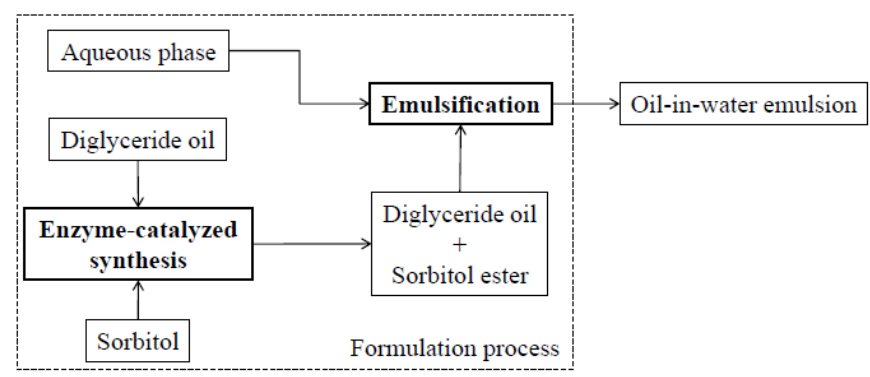

